\title{
ARQUEOLOGIA, SOCIEDADE E PODER: BREVES CONSIDERAÇÕES SOBRE UMA ARQUEOLOGIA DO PASSADO RECENTE
}

\author{
Adriano Batista dos Santos ${ }^{i}$
}

'Bacharel e Mestre em Arqueologia pela Universidade Federal de Sergipe/UFS e Graduando do Curso de Formação Pedagógica em História pelo Centro Universitário Leonardo da Vinci/UNIASSELVI. E-mail: adriano.abs@homail.com
Resumo: O presente artigo tem como objetivo sintetizar o conceito de uma Arqueologia do Passado Recente e o papel dos arqueólogos, enquanto agentes sociais, na sociedade que vivemos. Ao mesmo tempo, o texto pontua sobre os caminhos teóricos que levaram a Arqueologia, desde o seu surgimento, em meados do século XIX, até o campo pós-processualista dos dias atuais, além dos conceitos de poder embutidos na disciplina ao longo da sua trajetória. Todas essas informações nos permitem realizar reflexões acerca das práticas arqueológicas no contexto contemporâneo, seu campo de atuação, seus objetos de estudo e a responsabilidade dos arqueólogos na formação dos seus discursos.

Palavras-Chave: Arqueologia Contemporânea, Pós-Processualismo, Sociedade.

\begin{abstract}
This article aims to synthesize the concept of an Archeology of the Recent Past and the role of archaeologists, as social agents, in the society we live in. At the same time, the text points out the theoretical paths that led Archeology, since its emergence, in the mid-19th century, to the post-processualist field of today, in addition to the concepts of power embedded in the discipline throughout its trajectory. All this information allows us to reflect on the archaeological practices in the contemporary context, their field of action, their objects of study and the responsibility of archaeologists in the formation of their speeches.
\end{abstract}

Key Words: Contemporary Archeology, Post-Processualism, Society. 
Introdução

\begin{abstract}
Essa noite eu tive um sonho de sonhador / Maluco que sou, eu sonhei / Com o dia em que a Terra parou / Com o dia em que a Terra parou / / Foi assim / No dia em que todas as pessoas / Do planeta inteiro / Resolveram que ninguém ia sair de casa / Como que se fosse combinado em todo o planeta / Naquele dia, ninguém saiu de casa, ninguém / / O empregado não saiu pro seu trabalho / Pois sabia que o patrão também não tava lá / Dona de casa não saiu pra comprar pão / Pois sabia que o padeiro também não tava lá / $\mathrm{E}$ o guarda não saiu para prender / Pois sabia que o ladrão, também não tava lá / E o ladrão não saiu para roubar / Pois sabia que não ia ter onde gastar / / No dia em que a Terra parou / No dia em que a Terra parou...

(Trecho da música "O dia que a terra parou" de autoria de Claudio Roberto e Raul Seixas - Álbum: O dia Que a Terra Parou, gravadora Warner, 1977).
\end{abstract}

Quem diria que essa letra tão utópica de Raul Seixas, gravada em 1977 fosse dizer tanto no ano de 2020. Há quem diga que a canção foi inspirada em um sonho que Raul teve, outros dizem que a letra tem inspiração em um filme homônimo lançado em 1951. Independente da real origem dessa canção, o fato é que essa letra nunca foi tão atual. A situação pandêmica que o mundo enfrenta por conta do novo corona vírus forçou as pessoas a mudarem seus hábitos e rotinas drasticamente. Objetivando frear a disseminação do COVID-19 o mundo literalmente parou, populações foram orientadas a permanecerem em suas casas, comércios e indústrias foram fechados, parques e locais de lazer foram isolados. A circulação de pessoas ficou restrita a essencialidades, não nos restou outra alternativa a não ser seguir as orientações e permanecer o maior tempo possível em casa. Nesse contexto de isolamento social, com tempo para leituras e reflexões, este artigo foi concebido, como uma maneira de sintetizar os meus pensamentos em torno da ciência arqueológica e de nossas atuações na sociedade.

Este é o primeiro artigo que escrevo em cinco anos, em parte por estar envolvido em outras atividades de ordem pessoal e profissional. Esse distanciamento, não intencional, do ambiente acadêmico me auxiliou em vários aspectos. O tempo longe do universo acadêmico me permitiu uma reflexão mais aguda sobre alguns conceitos construídos durante todo o meu processo de formação acadêmica, assim como me ajudou também a reafirmar e até mesmo mudar algumas opiniões delineadas ao longo desses anos. Naturalmente esses processos me fizerem repensar algumas ideologias, a fim de me (re)encontrar enquanto arqueólogo - um ser social em meio a sociedade em que vivemos. 
Não atoa a canção de Raul Seixas se faz tão atual nesse momento de pandemia, o passado cruzando o presente em frases de um mundo que seria apenas imaginário até que a realidade nos mostrou o contrário. Nesse sentido, a Arqueologia, exercendo seu papel de uma ciência do hoje, e nós arqueólogos, enquanto agentes sociais, somos responsáveis pela compreensão da sociedade na qual vivemos. Pensando nisso, o presente artigo busca tecer breves considerações acerca de uma Arqueologia do Passado Recente e o posicionamento dos arqueólogos perante os estudos contemporâneos. Ao mesmo tempo, busco um panorama geral da disciplina e de suas habilidades em meio a sociedade atual.

\section{O Pensar Arqueológico - Uma Síntese dos Últimos Séculos}

A Arqueologia tem passado, nas últimas décadas, por grandes mudanças epistemológicas e, por consequência, em seus aspectos sociais (Funari, 2013). A percepção da Arqueologia em meio às práticas sociais é recente, tendo se iniciado na década de 1980, quando a Arqueologia esteve em contato com diversas estruturas da teoria social, desafiando a neutralidade e pedindo engajamento social e político (Funari, 2006). Para entendermos melhor esse contexto social da Arqueologia, precisamos retornar para a história do pensamento arqueológico. Desde seu surgimento, diversas teorias desenvolveram-se e, de certa forma, todas elas continuam até hoje sendo utilizadas (Funari, 2005).

\footnotetext{
Em linhas gerais, pode-se dizer que a história da arqueologia institucionalizada começa com o surgimento da figura do arqueólogo. Até o final do século XVIII, o estudioso da Antiguidade era o antiquário, que, a partir daí, é substituído pelo arqueólogo. Com a nova figura do arqueólogo, as pesquisas se desenvolveram na medida em que escavações foram sendo realizadas. Todavia, de início, as realizações eram de caráter individual, até que se tornasse coletiva ao longo do século XIX. Ainda que diferentes instituições tenham promovido o surgimento de uma ciência arqueológica e a institucionalização da disciplina, elas significaram também um interesse dos Estados pelo patrimônio monumental de seu passado, levando-os à apropriação dos mesmos e influenciando, assim, os rumos da pesquisa arqueológica (Funari, 2013).
}

O modelo histórico-cultural, originado no final do século XIX, parte do pressuposto que a cultura seja homogênea e que as tradições passem de geração a geração. Este modelo, ainda que tenha sofrido muitas críticas, continuou a ser o muito difundido na Arqueologia, em suas múltiplas variantes e formas. O primeiro contraponto consistente a esse paradigma viria daqueles que não praticavam a Arqueologia de cunho filológico e histórico, à maneira europeia. No contexto de uma Arqueologia antropológica norte-americana, surgiu um 
movimento, na década de 1960, que se autodenominava de New Archaeology ou Arqueologia Processual, tendo Lewis Binford sua principal voz e o seguinte grito de ordem: "a Arqueologia é Antropologia ou não é nada", em um claro desafio ao caráter histórico da Arqueologia histórico-cultural. Para os adeptos dessa nova linha de pensamento, a História estaria em busca dos eventos e das culturas singulares, enquanto a Antropologia americana ressaltava que haveria regularidades no comportamento humano. Buscavam-se então por leis transculturais de comportamento. Partindo do pressuposto que os homens maximizam os resultados e minimizam os custos, em qualquer época e lugar (Funari, 2005).

A Arqueologia Processual refletia bem uma visão capitalista do passado humano, privilegiando uma interpretação materialista pouco preocupada com as diversidades culturais. Surgida no contexto da Guerra Fria e tendo atingido seu ápice na década de 1970, ela continua bastante difundida, ainda que nunca tenha conseguido alcançar, em popularidade acadêmica, o modelo histórico-cultural (Funari, 2005). Ainda sobre a New Archaeology, Barreto (2013) destaca que um dos problemas da Arqueologia Processualista é que ela possui um viés positivista, já que vê os dados separados da teoria. Ou seja, os dados são entidades estáticas a serem explicados de forma objetiva, através de inferências e generalizações a respeito do passado. Partindo destes pressupostos cientificistas, a Nova Arqueologia pretendia ser um empreendimento mais científico, pois acusava o seu rival histórico-cultural de ser a-científico.

A partir da década de 1980, começaram a surgir críticas mais contundentes ao Processualismo. Nas Ciências Humanas, em geral, difundia-se o pós-modernismo e as críticas à ideia de verdade científica (Funari, 2005). No âmbito da Arqueologia, teve início um movimento que dava importância para a vida social dos objetos e o sentido simbólico que este assume dentro das sociedades estudadas, expandindo-se para além da abordagem tecno-econômica da Arqueologia Processual. Este novo olhar para os objetos foi chamado de Arqueologia Pósprocessual, ou Arqueologia Contextual. Uma de suas principais novidades foi o entendimento da cultura material como um texto que requer interpretação por parte do pesquisador, já que as interpretações dos arqueólogos são entendidas como discursos relativos (Barreto, 2013). 
As arqueologias denominadas pós-processuais de meados dos anos 1980, rechaçam o determinismo e a imparcialidade asséptica das arqueologias científicas. Argumenta-se que cada arqueólogo está fortemente midiatizado por suas experiências pessoais e por seu entorno, o que impossibilita um enfoque completamente objetivo dos problemas arqueológicos. Nesta corrente de pensamento, a arqueologia não descobre verdades, não descobre o passado; senão que o converte de forma criativa em um recurso útil para a sociedade que o (re)cria, a partir dos vestígios disponíveis (Shanks e Tilley, 1987).

Sob essa perspectiva, os arqueólogos passaram a ser entendidos por atores políticos, responsáveis pelos seus atos, em contato próximo com os nativos e as pessoas locais, bem como outros cientistas sociais. Assim, a Arqueologia foi redefinida, como sendo não apenas o estudo "dos povos e lugares antigos", mas "das relações de poder atuais" (Zarankin e Funari, 2009). Ao ressignificar o conceito de Arqueologia, construir/inventar/interpretar o passado passou a ser função básica do arqueólogo. Refletir sobre este processo tornou-se, portanto, o ponto central da prática arqueológica (Zarankin, 2014).

O conceito de poder, conectado à disciplina arqueológica, já vinha sendo aplicado desde o século XIX, no âmbito do imperialismo europeu, buscando, sobretudo, reafirmar a soberania de seus impérios perante outros povos. Esse sentimento desvirtuado de uma política nacionalista em conjunto com os pressupostos de poder pinçados da Arqueologia históricoculturalista cruzaram o século XIX, chegando até a Alemanha nazista de Hitler, onde o filósofo e arqueólogo Gustaf Kossinna, pautado em uma política nacionalista, desenvolveu teorias em busca da origem dos povos germânicos e indo-europeus. Suas teorias contribuíram para a construção da ideologia nazista, a mesma que reafirmava a superioridade da raça ariana e que ceifou a vida de milhões de judeus - um triste capítulo na historiografia mundial.

Com o desenvolvimento da Arqueologia Processual, concebida como um contra-ataque ao eixo subjetivista e impiricista praticado no histórico-culturalismo, a ênfase do conceito de poder migrou para o campo do rigor cientifico, os arqueólogos abstiveram-se de opiniões, concentrando-se na busca por padrões de regularidade das sociedades. Nesse sentido, o poder atribuído a Arqueologia estava intimamente entrelaçado com os resultados científicos obtidos. Anos mais tarde, os conceitos da New Archaeology são colocados a prova. Teóricos como lan Hodder, Chistopher Tilley, entre outros, passam a questionar as bases teóricas processualistas, além da ausência de envolvimento do arqueólogo junto aos seus objetos de estudo. Essa contestação deu origem a uma nova linha de pensamento, a chamada Arqueologia PósProcessual. 
Os conceitos Pós-Processuais trouxeram em suas bases teóricas o subjetivismo (que havia sido suprimido anteriormente pela nova arqueologia) e a interpretação dos fatos. Os arqueólogos, por sua vez, deixaram de ser meros espectadores da produção cientifica, e passaram a ser protagonistas do fazer arqueológico. Francisco Noelli (2001), em sua resenha do livro "Sed non satiata. Teoria social en la Arqueologia Latinoamericana Contemporanea", pontua que para os organizadores do volume, o inconformismo com a disciplina, tal qual se apresentava, era tão grande quanto o daqueles jovens e insatisfeitos arqueólogos fundadores da New Archaeology. Se no início dos anos 1960 buscava-se uma abordagem mais científica e antropológica, no início dos anos 1990 procurava-se abordagens mais politizadas em torno do confronto entre classes sociais, do exercício do poder, das questões de gênero, da etnicidade, da circulação econômica, da sexualidade, da relação com o ambiente e da própria inserção do arqueólogo como ator no meio acadêmico e social.

Nesse contexto de uma Arqueologia de cunho social, o World Archaeological Congress, fundado em 1986, traz um desafio claro à Arqueologia tradicional, reacionária (no melhor dos casos) ou neutra, em favor da consideração das ciências sociais (Zarankin e Funari, 2009). Os arqueólogos procuram fugir das explicações normativas e monolíticas fora do "consenso ortodoxo", bem como de eventuais "receitas de bolo", dirigindo-se intrépidos em busca da dinâmica da vida social e da produção cultural, defendendo a posição de que não há mais observações teóricas neutras (Noelli, 2001).

\begin{abstract}
A Arqueologia está ligada à aventura, ao mistério, ao perigo e à fantasia no imaginário do público. Indiana Jones representa o paradigma social do arqueólogo. Desse ponto de vista, é difícil conceber a Arqueologia como uma disciplina interessada em analisar a nossa própria sociedade. Por sorte, há alguns anos os arqueólogos passaram a questionar a natureza do conhecimento que eles produziam, bem como as consequências disso para as pessoas. Dessa perspectiva, a Arqueologia tonou-se uma ferramenta política útil para transformar a sociedade (Zarankin e Funari, 2009).
\end{abstract}

As novas diretrizes apresentadas pela Arqueologia Pós-Processual trouxeram mudanças na forma do pensar arqueológico. O poder existente na disciplina, outrora utilizado para legitimar sociedades dominantes ou para reafirmar conceitos científicos absolutos, agora passa para a tutela dos arqueólogos, detentores das interpretações de seus objetos de estudo. Assim, a Arqueologia passa a ser um instrumento político na busca de histórias alternativas do passado. 
Dentre as teorias sobre poder de maior impacto nas ciencias sociais, devemos mencionar uma ideia marxista de poder e uma outra foucaltiana. De maneira simplificada pode-se-ia dizer que os marxistas partem de uma concecpção essencialista hegeliana, no qual o poder é exercido por uma classe dominante em antagonismo a uma classe dominada. Isso implica imaginar um macropoder de carater negativo, que serve para manter as condições de exploração de uma classe sobre a outra. Por sua parte, Foucaut introduz a ideia de micropoderes. Para este autor, o poder não se possui, mas se exerce: não existem dominadores e dominados, senão que variam em função do contexto que estão inseridos. Por exemplo: Um operário pode ser objeto de poder dentro de uma fábrica, mas, paralelamente, na sua casa, é o que exerce o poder sobre a mulher e os filhos (Zarankin, 2001).

Em tese, essas novas concepções apontam a Arqueologia como uma disciplina ampla, dialógica e humilde, podendo chegar a qualquer pessoa ou grupo, sem distinção de crença, classe social, gênero, etc (Santos, 2016). Os arqueólogos atualmente, tem se dedicado a estudar não só os objetos em si, mas a todo o contexto em que estes artefatos estão inseridos (Funari, 2007). A Arqueologia como uma forma de interpretação permite a possibilidade de jogar com as evidencias para formar diferentes visões de como acreditamos que tenha sido o passado. A pluralidade de leituras mostram que sempre uma interpretação poderia ter sido criada de forma distinta (Zarankin, 2001).

O subjetivismo proposto pelos pós-processualistas e a aproximação da Arqueologia com as questões sociais permitiram o desenvolvimento de inúmeras linhas de pesquisa no âmbito da Arqueologia, abordando temáticas antes negligenciadas pelos pesquisadores, além disso, esses novos pressupostos permitiram também lançar histórias alternativas sobre temáticas amplamente difundidas, levando em consideração que não existe verdades únicas e sim construções dos mais variados pontos de vista.

\section{Por Uma Arqueologia do Passado Recente}

Como podemos ver, as bases ideológicas da Arqueologia sempre estiveram em constante movimentação, e isso propiciou a formulação de uma Arqueologia interessada nos estudos do passado recente. A Arqueologia do Passado Contemporâneo é um campo que vem se consolidando cada vez mais dentro da disciplina, tendo se iniciado por volta do ano de 2001, com a publicação do clássico livro de Victor Buchli \& Gavin Lucas - Archaeologies of the Contemporary Past, condensando artigos de temáticas contemporâneas de diferentes partes do mundo (Gonzalez-Ruibal, 2019). A Arqueologia Contemporânea, como se observa, oferece 
uma gama variada e interessante de possibilidades. Como resultado, suas aplicações podem ser direcionadas para diversas áreas, como a Arqueologia urbana, gestão, universidade, instituições públicas, associações, etc. Além de uma análise histórica do século $X X$, e especialmente, os vários conflitos que indispensavelmente moldaram a Arqueologia, que é uma ciência que permite recuperar e interpretar os restos materiais do passado, contribuindo assim, com sua metodologia e suas perspectivas para o conhecimento mais preciso e rigoroso que pode ser compartilhado e divulgado para a sociedade (Garcia, 2013).

O património arqueológico integra estruturas, construções, grupos de edifícios, locais desenvolvidos, bens móveis e monumentos de outra natureza, bem como o respectivo contexto, quer estejam localizados em terra ou debaixo d'água. Ou seja, os restos enterrados ou submersos, desde que eles fornecem informações sobre "a história da humanidade e sua relação com o ambiente natural". Este novo campo na disciplina se estende até os limites cronológicos estabelecidos pela história, ou seja, a nível mundial, desde o início do século XX até os dias atuais (Olivier, 2001).

Além dessas definições básicas, a situação dos vestígios do passado contemporâneo é complexa, pois eles estão imersos em nosso presente (Olivier, 2001). Nesse sentido, o termo contemporâneo deve ser caracterizado de forma difusa, levando em consideração que a Arqueologia não pode ser considerada em termos de limitações cronológica, mas em torno da articulação de relações entre passado e presente, cultura material, individual e grupos. Podese até pensar que mais do que visões de Arqueologia Contemporânea, são visões de problemas contemporâneos sob perspectivas arqueológicas (Gonzáles, et al, 2014).

Com base na Convenção Europeia Para Proteção do Patrimônio Arqueologico (também conhecida como Convenção de Malta), Laurent Olivier (2001) afirma que os restos de um passado recente são vestígios arqueológicos totalmente distintos devido a nossa relação próxima com os lugares, objetos, modos de vida ou práticas que ainda são nossas e que alimentam uma identidade coletiva. Com isso, os estudos arqueológicos de periodos contemporâneos flertam diretamente com o campo da história, uma vez que seus objetos de estudo estão imersos na historiografia da nossa sociedade atual, levantando questões sobre os limites das práticas arqueológicas nesses contextos recentes. Sobre o exposto, Vitor Jorge (1990) aborda essa relação da seguinte forma: 
Os saberes são realidades históricas, resultam de compartimentações herdadas, sem nada de necessário ou de "natural”, e eternizam-se a maior parte das vezes como tais em resultado dos interesses dos seus detentores. São carreiras, empregos e outras formas de organização da comunidade científica que estão em causa, implantadas no terreno, cada uma com suas clientelas e com seu maior ou menor impacto social. São "corredores" por onde se pode ascender numa certa hierarquia, com suas regras próprias. Por isso, se declararmos que a Arqueologia não é, ou não deve ser, um domínio secundário ou marginal, mas uma forma própria de fazer história e de perspectivar a realidade humana, estamos a tomar uma importante posição no jogo político dos saberes, no âmbito das ciências sociais. Estamos a admitir que ela é uma atividade aberta, porosa em relação a outras disciplinas, e capaz de lhes disputar um papel de relevo no conjunto da cultura contemporânea. A Arqueologia é, para nós, um saber alternativo ao da história tradicionalmente considerada. É uma forma própria de estudar o mundo material, o mundo da relação do homem com a realidade física que o rodeia e de que ele mesmo faz parte.

Do ponto de vista metodológico, a Arqueologia dos vestígios contemporâneos não pode ser reduzida a um empreendimento unívoco, confinado apenas a especialistas na análise dos vestígios materiais do passado, sendo eles arqueólogos ou cientistas habitualmente associados a esses vestígios. Pela própria natureza dos materiais a serem tratados, a Arqueologia do passado recente só pode ser compreendida levando em conta suas "várias vozes", no qual diferentes grupos profissionais ou políticos estão envolvidos, juntamente com as diversas comunidades sociais ou culturais que se interessam pelo que estes vestígios se tornaram e pelo significado que dá à história que testemunharam (Olivier, 2001).

Esta Arqueologia multivocal, em que a memória coletiva ou o testemunho de indivíduos goza de uma autoridade normalmente concedida apenas a especialistas do passado, exige que, a nível teórico, reconsideremos a questão da construção da interpretação arqueológica. A Arqueologia do passado contemporâneo está, com efeito, diretamente confrontada com o problema da significação presente dos vestígios do passado e com a diversidade de interpretações, de acordo com as perspectivas e abordagens em questão. O estudo do funcionamento interno e do lugar ocupado pela Arqueologia e pelos arqueólogos, em cada situação, dentro desta rede de inter-relações, constitui um aspecto essencial do procedimento interpretativo da disciplina (Olivier, 2001).

Resumindo, é possível definir a Arqueologia do Passado Recente, ou simplesmente Arqueologia Contemporânea, como sendo uma área da Arqueologia que se propõe a estudar um passado ainda presente na memória da sociedade. Os estudos desse passado contemporâneo tem sua sustentação nos conceitos pós-processualistas desenvolvidos durante 
a década de 1980, onde a Arqueologia se aproximou das ciências sociais, transformando-se em um importante instrumento de vocalização de grupos antes marginalizados ou esquecidos. Além de auxiliar na construção de histórias alternativas aos discursos oficiais. O poder de apresentar múltiplas versões sobre um mesmo tema, faz da Arqueologia Contemporânea uma ferramenta importante na compreensão da nossa própria sociedade, a exemplo, o modo de vida das pessoas antes da pandemia que atingiu todo o planeta e como as sociedades se comportarão daqui pra frente, em um mundo pós pandemia. No sentido técnicometodológico, não há muitas diferenças no modo como os vestígios são tratados, há não ser pela forma de interpretação desses artefatos, uma vez que será preciso compreender toda sua carga histórica envolvida.

Por fim, do ponto de vista ético, os riscos envolvidos na Arqueologia do Passado Contemporâneo exigem que pensemos de forma diferente a interpretação do passado e 0 papel desempenhado, em graus diversos, mas complementares, pelos indivíduos e coletividades engajadas no processo de construção da história. Portanto, o funcionamento da Arqueologia do Passado Contemporâneo não é centralizado ou piramidal, à maneira da produção e difusão tradicionalmente organizada do conhecimento. Ao contrário, na nova configuração da Arqueologia Contemporânea, a informação circula em rede e é trocada em todos os níveis da estrutura, sem uma hierarquia pré-definida que restrinja sua exploração. Assim, a Arqueologia Contemporânea faz parte do desenvolvimento de novas formas de cidadania, nas quais os problemas da coletividade são desnudados e discutidos por agrupamentos de indivíduos em todos os níveis, do mais simples ao mais abrangente, enquanto as soluções para esses problemas são investigados por meio da inter-relação permanente dessas diferentes escalas de organização coletiva (Olivier, 2001).

\section{Considerações Finais}

As Arqueologias Pós-Processuais têm salientado a subjetividade do conhecimento arqueológico, construído no presente, a partir de contextos sociais, políticos, econômicos e culturais que influenciam a produção científica. Uma das principais questões colocadas por essas Arqueologias reside nos significados simbólicos dos vestígios arqueológicos, que variam de contexto para contexto (Wichers, 2015). Como arqueólogos, criamos um discurso sobre o passado, traduzindo objetos em relatos. Por isso os articulamos de modo que nossas características do passado tenham coerência e sentido para todos. Ao adotarmos uma postura 
ativa no processo de formação do discurso arqueológico, colocamos nossa pesquisa num lugar de compromisso social, procurando debater aspectos que contribuam para criticar as desigualdades da sociedade em que vivemos (Zarankin, 2001).

Para Funari (2007), talvez o mais importante ganho da Arqueologia nos últimos anos, tenha sido o engajamento dos seus profissionais com o público. Contudo, entendo que muito já foi feito nesse sentido, porém, precisamos tecer mais reflexões sobre como nos dirigimos a esse público e mais importante, quem é esse público a qual a disciplina se direciona. No escopo das mais variadas temáticas de estudo da Arqueologia, há uma área dedicada ao estudo desse viés público da disciplina - A Arqueologia Pública, da qual pretendo discorrer em publicações futuras. Muito se fala sobre uma Arqueologia dialógica e aberta, proposta a conversar com outras disciplinas e com o público em geral, porém alguns arqueólogos tem, por hábito, dialogar apenas para seus pares, mantendo-se, muitas vezes em suas zonas de conforto, produzindo e publicando uma ciência que dificilmente chegará ao grande público. Talvez esse seja um dos motivos que fazem a Arqueologia brasileira ainda soar como algo exótico e diferente aos ouvidos das pessoas.

Pensemos da seguinte forma: Nós arqueólogos e pessoas ligadas a nossa área compreendem os benefícios e a importância da Arqueologia para a sociedade, mas e as pessoas comuns? Pessoas que tiveram pouco ou nenhum contato com esse universo. Como explicar para estas pessoas que a Arqueologia é uma disciplina como qualquer outra e que o nosso trabalho não é algo distante da nossa realidade? O contato da Arqueologia com o público não pode ficar reduzido apenas a ações de educação patrimonial conectadas a grandes empreendimentos ou a matérias jornalísticas sobre achados arqueológicos relevantes, é preciso popularizar os estudos arqueológicos, mostrando para a sociedade que o fazer arqueológico é algo mais próximo do que se imagina. E sobre essa perspectiva, a Arqueologia de um Passado Recente traz importantes contribuições ao abordar temas contemporâneos, contidos no âmbito da sociedade em que vivemos, elencando debates e opiniões que envolvam o grande público, mostrando, sobretudo, a importância desse público no contexto de uma Arqueologia socializada.

Louise Alfonso (2012) pontua que o conhecimento do passado tem uma clara função social, que faz parte das ideologias que configuram o nosso mundo e a nossa identidade. Os arqueólogos devem se desprender da ingenuidade de uma neutralidade imposta pela ciência ocidental e pelo capitalismo e assumir que o seu trabalho tem efeitos sociais importantes, e 
que eles obviamente não tem motivo algum para cair em um paternalismo igualmente ingênuo, tampouco para deixar de fazer Arqueologia. Pelo contrário, trata-se de seguir fazendo ciência, porém, com "consciência", aceitando o diálogo e a participação dos outros, assim como mantendo uma postura crítica. Já Luís Cláudio Symanski (2009) ao discorrer sobre os processos de formação da Arqueologia Histórica brasileira, salienta para uma forte influência da concepção marxista de que as ideologias dos grupos dominantes são impostas aos subordinados através de representações que servem para naturalizar a arbitrariedade da ordem social. Segundo ele, as vertentes pós-modernas focalizadas no discurso têm levado esta premissa ao seu extremo, considerando a própria produção arqueológica como uma representação, uma manipulação maniqueísta, que pode servir ao interesse de diferentes grupos de uma sociedade, ou, em um nível mais amplo, como uma das formas pelas quais as potências ocidentais impõem sua visão de mundo sobre outros povos. Symanski (2009) ainda afirma que é importante lembrar que posições extremistas, sejam objetivistas ou relativistas, apresentam um risco muito grande de tornarem-se verdades absolutas, gerando assim um autoritarismo intelectual que pode ser extremamente nefasto para as ciências sociais.

Exemplificando as afirmações de Alfonso e Symanski, na última década houve uma crescente polarização política no País, polarização essa que ficou amplamente difundida após as eleições presidenciais de 2018, que promoveu um racha ideológico na nação. De um lado grupos alinhados à ideologias de esquerda, do outro, grupos de direita e conservadores. Nesse contexto, os arqueólogos, em sua maioria, marcaram suas posições ideológicas, majoritariamente, inclinados aos discursos da esquerda. Levando em consideração o papel social do arqueólogo e o poder do seu discurso na sociedade, alguns profissionais, imersos no discurso marxista de dominantes e dominados, ultrapassam os limites da compreensão social e elevaram o tom de seus discursos ao extremo. Até hoje é possível ver colegas de profissão esbravejando sobre como é difícil acreditar que exista "arqueólogos de direita" ou em casos mais radicais, é possível ver arqueólogos vindo a público, através das redes sociais, para cortar relações com outros colegas, pelo simples motivo deles possuírem opiniões políticas divergentes.

É perfeitamente compreensível que, no contexto de uma Arqueologia Social que desafia a neutralidade e arqueólogos, carregados de seus simbolismos e emoções, tenham todo o direito à manifestação de suas opiniões, a debater temáticas e a praticar diálogos concisos e conscientes. Entretanto, é preciso termos cautela, como o próprio Symanski alerta, pois 
posições extremistas e autoritarismos intelectuais são maléficos para as ciências sociais. Posicionamentos nesse sentido, como as praticadas por alguns arqueólogos, são no mínimo, contraditórias, uma vez que estes profissionais se propõem a estudar as sociedades, a dar voz a grupos negligenciados, a conversar com pessoas simples, que muitas vezes se sentem intimidadas pela nossa posição acadêmica. É inconcebível que profissionais que gerenciem tal carga de poder, se permitam praticar discursos de intolerância para com indivíduos que possuem ideologias diferentes as suas. Devemos expurgar ações desse tipo da comunidade arqueológica, dando ênfase a uma Arqueologia mais plural e dialógica, com arqueólogos que respeitem as opiniões do próximo e que não se utilizem do poder intelectual que possuem para oprimir ideias contrárias, caso contrário, estaremos fadados a produzir novos Hitlers.

Independente da ideologia política adotada, somos seres sociais, administradores do poder de contar histórias, temos a responsabilidade de apresentar múltiplas visões para a sociedade e de lutar, com as armas que possuímos, na busca de uma melhor compreensão das sociedades, sendo elas passadas ou atuais. Não obstante, devemos ser fiéis ao que a própria constituição brasileira nos impõe em seu artigo 5‥ A constituição federal é taxativa e sem margens para interpretações: "Todos são iguais perante a lei, sem distinção de qualquer natureza" (Brasil, 1988). Portanto, independente da opinião exposta, todos devem ser vistos de forma igualitária, com seus direitos e deveres constitucionais respeitados, e não seria a Arqueologia, tampouco os arqueólogos a desafiarem essa premissa.

Ao longo desse texto, busquei expor uma Arqueologia preocupada com o social, trazendo para o eixo das atividades arqueológicas os estudos do contemporâneo. Os arqueólogos, por sua vez, se tornaram agentes sociais responsáveis pelas leituras e interpretações dos artefatos de um passado recente, muitas vezes, possuindo memórias latentes para seus povos. A Arqueologia Pós-Processual, conforme explicitado no texto, permitiu o surgimento de várias possibilidades de estudos, trazendo à luz a muitas temáticas, antes desconsideradas pelos pesquisadores. Esse momento de isolamento social me levou a uma introspecção sobre qual é nosso papel na sociedade. Os estudos arqueológicos de períodos contemporâneos se fazem um importante instrumento na composição do mundo pós-pandemia. Como a sociedade se comportará com o novo normal? Será que o mundo, tal qual conhecíamos, voltará a existir? Perguntas e reflexões que provavelmente só serão respondidas com o tempo. Cabe a nós, arqueólogos, estarmos prontos para responder estas e outras perguntas para as próximas gerações, e cabe a mim, enquanto arqueólogo e aspirante a historiador, conciliar Arqueologia 
e História na compreensão da sociedade onde eu mesmo, enquanto agente social, estou inserido.

\section{Referências}

ALFOLSO, L. P. 2012. Arqueologia e Turismo: Sustentabilidade e Inclusão Social (Tese de Doutorado). Programa de Pós Graduação em Arqueologia do Museu de Arqueologia e Etnologia da Universidade de São Paulo/USP. São Paulo-SP.

BARRETO, B.S. 2013. Historiografia e Interfaces: Um Diálogo Entre História, Antropologia e Arqueologia. Revista de Teoria da História. Ano 5, no 9, Jul/2013. Pag. 247-279.

BRASIL. 1988. Constituição da República Federativa do Brasil de 1988. Disponível em: <http://www.planalto.gov.br/ccivil_03/constituicao/constituicaocompilado.htm>. Acesso em: 10/08/2020.

FUNARI, P.P.A. 2005. Teoria e Método na Arqueologia Contemporânea: O Contexto da Arqueologia Histórica. Mneme - Revista de Humanidades: Departamento de História e Geografia da Universidade Federal do Rio Grande do Norte. Vol.6, no.13. Pag. 1-5.

FUNARI, P.P.A. 2006. Arqueologia. Contexto. 2a ed. São Paulo-SP.

FUNARI, P.P.A. 2007. Teoria e a Arqueologia Histórica: A América Latina e o Mundo. Vestígios Revista Latino-Americana de Arqueologia Histórica, vol.1, no1. Pág. 51-58.

FUNARI, P.P.A. 2013. Arqueologia no Brasil e no Mundo: Origens, Problemáticas e Tendências. Ciência e Cultura, Vol.65, no.2: Pág. 23-25.

FUNARI, P.P.A. ZARANKIN, A. 2009. Brilho Eterno de Uma Mente Sem Lembranças: Arqueologia e Construção de Memória da Repressão Militar na América dos Sul (1960-1980). In: SOARES, I.V.P. at al.(Orgs). Arqueologia, Direito e Democracia. Habilis. Erechim-RS. Pág. 3149.

GARCIA, R. A. C. 2013. Arqueología Contemporáea: Las Fosas Comunes de Gualchos y Pinos Del Valle (Granada). In Arqueología e Territorio. no 10. Pág. 161-182.

GONZÁLES, P. A.; FRANCO, L. G.; OLIVEROS, J. C. M. 2014. Visiones Periféricas: Arqueología Contemporánea, Crítica y Política. Habitus. Vol.12. no.1. Goiânia/GO. Pág. 161-184.

GONZALEZ-RUIBAL, A. 2019. Arqueología Del Passado Contemporáneo: Uma Mirada Desde La Penísula Ibérica. Vestígios - Revista Latino-Americana de Arqueologia Histórica. Vol. 13, no2, Pág. 4-7.

JORGE, V.O. 1990. Arqueologia e História: Algumas Reflexões Breves. Revista da Faculdade de Letras - Instituto de Arqueologia, Faculdade de Letras. Universidade do Porto. Porto/Portugal, Vol.7, Pág. 367-372. 
NOELLI, F.S. 2001. Sed non satiata. Teoria social en la Arqueologia Latinoamericana Contemporanea (Resenha). Revista de Antropologia - USP, São Paulo. Vol.44. no.2. Pág. 235238.

OLIVIER, L. 2001. The Archaeology Of The Contemporary Past. In BULCHI, V. GARVIN, L. (Eds). The Archaeology Of The Contemporary Past. Routledged. New York/London, Pág. 175-188.

SANTOS, A.B. 2016. Arqueologia e Contemporaneidade: Reflexões Sobre os Locais de Repressão e Resistência do Regime Militar em Aracaju-Sergipe (Dissertação de Mestrado). Programa de Pós Graduação em Arqueologia da Universidade Federal de Sergipe/UFS. Laranjeiras/SE.

SHANKS, M. \& TILLEY, C. 1987. Social Theory And Archaeology. Albuquerque, University of New Mexico Press.

SYMANSKI, L. C. 2009. Arqueologia Histórica no Brasil: Uma Revisão dos Últimos Vinte Anos. In: MORALES, W. F. e MOI, F. P. (Orgs:) Cenários Regionais de uma Arqueologia Plural. Ed. Annablume/Acervo. Pág. 1-29.

WICHERS, C. A. M. 2015. Museus, Ações Educativas e Prática Arqueológica no Brasil Contemporâneo: Dilemas, Escolhas e Experimentações. Revista do Programa de Pós Graduação em Ciência da Informação da Universidade de Brasília: Museologia e Interdisciplinaridades. Vol.3, no6. Pág. 109-134.

ZARANKIN, A. 2001. Paredes que Domesticam: Arqueologia da Arquitetura Escolar Capitalista: O Caso de Buenos Aires (Tese de Doutorado). Universidade Estadual de Campinas - UNICAMP. Campinas/SP.

ZARANKIN, A. 2014. "A Persistência da Memória"... Histórias Não-Lineares de Arqueólogos e Fogueiros na Antártica. Revista de Arqueologia - SAB. vol. 27, no2. Pág. 35-46. 